\title{
Strong hydrological stress homogenized soil carbon of three main soil types in the reservoir riparian zone
}

\author{
Yiguo Ran ${ }^{1}$, Jan Frouz ${ }^{2}$, maohua ma ${ }^{1}$, Yue Zhou ${ }^{1}$, Imali Kaushalya Herath ${ }^{1}$, shengjun wu ${ }^{1}$, \\ and Ping Huang ${ }^{1}$ \\ ${ }^{1}$ Chinese Academy of Sciences \\ ${ }^{2}$ Univerzita Karlova
}

June 8, 2020

\begin{abstract}
soil types differentiated the response of their properties to environmental disturbance. Despite the impact of hydrological stresses on soil properties being widely reported in riparian zones, little is known about how the effect of hydrological stresses on soil carbon dynamics varies among soil types. Here we have studied the effect of hydrological stresses and soil types on organic carbon fraction, carbon concentration in bulk soils and aggregate fractions, total carbon content, $\mathrm{pH}$, bulk density and soil mechanical compositions. The results showed that hydrological stresses induced by around 10 years' of operation of the Three Gorges Reservoir not only had a direct impact on carbon contents and carbon fractions, but also had an indirect impact on carbon contents via modifying edaphic factors including soil aggregates and carbon fractions in the riparian zone. Soil types were differentiated in the response of their physical properties to the weak and non- hydrological stresses. However, the original differences of soil physical properties among three main soil types were homogenized by the strong hydrological stress, which can be indicated by a small macro-aggregate proportion and fine particulate organic carbon concentration. Additionally, more than $3.95 \mathrm{Tg}$ of carbon was stored in the topsoil of the whole riparian zone of the Three Gorges Reservoir, and the lowest stability but highest carbon storage was in Regosols. Much attention should be given to this. Further studies are recommended to focus on carbon saturation in different soil types under different hydrological stresses.
\end{abstract}

\section{Hosted file}

Manuscript.docx available at https://authorea.com/users/331127/articles/457936-stronghydrological-stress-homogenized-soil-carbon-of-three-main-soil-types-in-the-reservoirriparian-zone 